Gut, 1976, 17, 595-599

\title{
Disappearance half-time of endogenous and exogenous secretin in dogs ${ }^{1}$
}

\author{
P. J. CURTIS, H. R. FENDER, P. L. RAYFORD, AND J. C. THOMPSON² \\ From the Department of Surgery, The University of Texas Medical Branch, Galveston, Texas, USA
}

SUMMARY We have used a sensitive and specific radioimmunoassay to measure the disappearance half-times of exogenous porcine secretin and endogenous canine secretin in the dog and found them to be 2.45 and 2.85 minutes, respectively.

Since the discovery of secretin in 1902 by Bayliss and Starling, quantitative estimations of secretin activity have been based on the ability of the hormone to stimulate flow of bicarbonate-rich pancreatic juice. Since about the time of the initial isolation of the hormone from hog intestine by Jorpes and Mutt (1959), there have been refinements in bioassay technique (Ivy and Janecek, 1959; Mutt and Söderberg, 1959; Heatley, 1968) which have produced considerable standardisation of results. Unfortunately, these techniques lacked specificity and precision, and were incapable of measuring basal levels of secretin in the circulating plasma of animals and man. Calculations of the disappearance half-time $\left(\mathrm{T}_{\frac{1}{2}}\right)$ of secretin were, however, made in laboratory animals using pancreatic secretion as an index of secretin activity (Clark et al., 1967; Lehnert et al., 1969; Hubel, 1972).

We have recently validated a radioimmunoassay which is both sensitive and specific and can accurately measure concentrations of secretin of less than $20 \mathrm{pg} / \mathrm{ml}$ in plasma (Rayford et al., 1976).

Using this assay technique, we have measured plasma levels of secretin in dogs after an infusion of pure natural porcine hormone and have calculated its disappearance half-time. We have also measured basal and stimulated levels of endogenous secretin in dogs and have calculated its disappearance halftime.

\section{Methods}

DISAPPEARANCE HALF-TIME OF EXOGENOUS SECRETIN

Eight fasting, adult, mongrel dogs weighing ap-

${ }^{1}$ Supported by a grant from the National Institutes of Health (AM 15241).

2Address for correspondence: Dr. J. C. Thompson, Department of Surgery, The University of Texas Medical Branch, Galveston, Texas 77550, USA.

Received for publication 28 April 1976 proximately $20 \mathrm{~kg}$ were placed in Pavlov stands and an intravenous catheter placed in a foreleg and a hind leg of each dog. After collecting two $5 \mathrm{ml}$ basal blood samples, 10 minutes apart, each dog received an infusion of pure natural secretin (Professor V. Mutt, Gastrointestinal Hormone Laboratory [GIH], Karolinska Institute, Stockholm), 1.5 unit/kg body weight, dissolved in $50 \mathrm{ml} 0.9 \% \mathrm{NaCl}$. This secretin preparation contains 3500 clinical units/mg. The infusion was delivered over 30 minutes into a foreleg vein using a Harvard syringe pump. Blood samples were collected from the hind leg catheter at five-minute intervals during the infusion. The infusion was then terminated and samples collected at one-minute intervals for 10 minutes, then at two-minute intervals for 10 minutes.

DISAPPEARANCE HALF-TIME OF ENDOGENOUS SECRETIN

A further six fasting, adult, mongrel dogs were anaesthetized with intravenous sodium pentobarbital $(25 \mathrm{mg} / \mathrm{kg})$, and the abdomen opened. A segment of bowel, comprising the whole of the duodenum and the proximal $50 \mathrm{~cm}$ of the jejunum, was prepared for stimulation of secretin release by ligation of the pylorus, ligation of the superior pancreaticoduodenal vein at its entry into the portal vein, and division of the jejunum and its mesentery $50 \mathrm{~cm}$ distal to the ligament of Treitz. A cannula was introduced into the proximal duodenum for infusion of acid, and the distal end of the segment of bowel was left open to allow free drainage of the infusate into a basin. The venous drainage of this segment of bowel flowed caudally in the inferior pancreaticoduodenal vein and jejunal veins to enter the superior mesenteric vein. A ligature was passed loosely around the entire vascular pedicle of the isolated segment of bowel and was left untied.

Two basal blood samples were collected at an interval of 10 minutes from a catheter in a jugular 
vein, after which $0.1 \mathrm{~N}$ hydrochloric acid was infused into the isolated duodenojejunal loop at the rate of $1.5 \mathrm{mEq} / \mathrm{min}$ using the Harvard syringe pump. Five-millilitre blood samples were collected at five-minute intervals during the infusion, and after its termination, at one-minute intervals for 10 minutes and then two-minute intervals for 10 minutes. After exactly 20 minutes of stimulation with $\mathbf{H C l}$, the perivascular ligatures were quickly tied, suddenly and completely occluding the venous drainage of the stimulated segment of bowel.

In all studies, $5 \mathrm{ml}$ blood samples were collected in chilled tubes containing 2000 kallikrein inactivator units (k.i.u.) of trasylol (Aprotinin) and $125 \mathrm{u}$ sodium heparin. Samples were centrifuged at $4^{\circ} \mathrm{C}$ and the plasma stored at $-20^{\circ} \mathrm{C}$ for subsequent radioimmunoassay for secretin. Estimations of secretin were performed in duplicate and the mean value used. Results are expressed as mean values plus or minus the standard error. Statistical significance of differences was assessed by means of Student's $t$ test for paired data; P values of less than $5 \%$ were taken to be significant. Disappearance curves of secretin were subjected to linear regression analysis.

\section{RADIOIMMUNOASSAY TECHNIQUE}

The assay was developed by Rayford et al. (1970). Details of the method will be presented for clarity. The secretin immunoassay employs antibodies raised in white New Zealand rabbits to pure natural porcine secretin (GIH). The antibody binds $30 \%$ to $40 \%$ of 125I secretin at a final dilution of 1:50,000. Synthetic 6-tyrosyl secretin (Schwarz-Mann) was radioiodinated by the method of Greenwood et al. (1963); the labelled hormone was separated from contaminants by gel filtration. The double antibody technique described by Odell et al. (1967) was used to separate bound from free hormone. Graded amounts of pure natural porcine secretin (GIH) were used to prepare a standard curve, and dose interpolation was performed using the log-logit transformation method of Rodbard (1971). When the curve is calculated by this method, we find that we can detect quantities of secretin as small as $5 \mathrm{pg} /$ assay tube with $95 \%$ confidence. Since the assay is conducted using $300 \mu \mathrm{l}$ of sample, the lower limit of detection in the system is about $15 \mathrm{pg} / \mathrm{ml}$ of sample. The variation of results within each assay was less than $5 \%$ and that between assays was less than $13 \%$.

There is no cross-reaction in the assay system with synthetic human gastrin I, glucagon, gastric inhibitory peptide, or $99 \%$ pure cholecystokinin (GIH). Minimal cross-reaction was seen with vasoactive intestinal peptide (GIH) presumably because of contamination with secretin.
Results

DISAPPEARANCE HALF-TIME OF EXOGENOUS SECRETIN

The basal level of secretin was $35 \pm 19 \mathrm{pg} / \mathrm{ml}$ and rose to a mean plateau level of $632 \pm 41 \mathrm{pg} / \mathrm{ml}$ over the last 15 minutes of secretin infusion. After the termination of the infusion at 30 minutes, secretin levels fell sharply, reaching $144 \pm 27 \mathrm{pg} / \mathrm{ml}$ at 36 minutes and attaining basal levels at 42 minutes (Fig. 1).

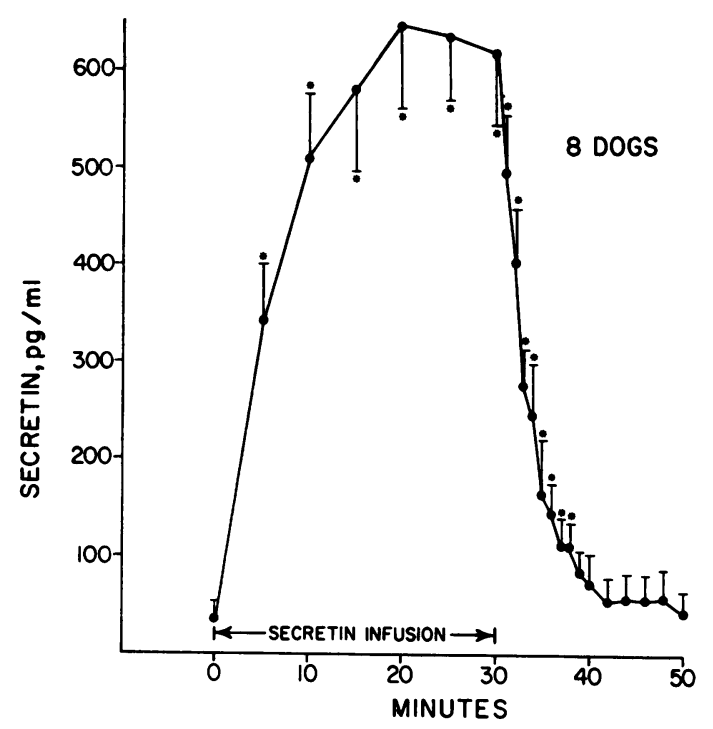

Fig. 1 Concentration of secretin in plasma before, during, and after constant rate intravenous infusion of pure natural secretin, $1.5 \mathrm{U} / \mathrm{kg}$ body weight, over 30 minutes. Asterisks denote significant elevations above basal $(P<0.05)$.

In calculating the disappearance half-time, the basal level of secretin was subtracted from all subsequent values. The postinfusion levels were then expressed as a percentage of the mean plateau level, and these values were converted to their natural logarithms. When examined by linear regression analysis by the method of least squares, it was found that the linear relationship between secretin concentration and time could be expressed by the equation used by Goldstein et al. (1968):

$$
y=a+b x
$$

where: $y=$ the natural logarithm of the concentration $(\mathrm{pg} / \mathrm{ml})$;

$a=$ the intercept;

$\mathrm{b}=$ the slope of the regression line;

and $x=$ the time (minutes).

The correlation coefficient of the regression line was 
-0.997 and its slope, -0.276 (Fig. 2). The disappearance half-time was determined by dividing the slope of the regression line into 0.693 (the natural logarithm of 2). The half-time of exogenously infused natural secretin in these dogs was 2.48 minutes.

DISAPPEARANCE HALF-TIME OF ENDOGENOUS SECRETIN

The mean basal secretin level in the six dogs was $112 \pm 14 \mathrm{pg} / \mathrm{ml}$. At the onset of duodenal perfusion with $\mathrm{HCl}$, levels rose rapidly to a mean value of $349 \pm 98 \mathrm{pg} / \mathrm{ml}$ at 10 minutes, $368 \pm 69 \mathrm{pg} / \mathrm{ml}$ at 15 minutes, and $470 \pm 125 \mathrm{pg} / \mathrm{ml}$ at 20 minutes. The levels at 10,15 , and 20 minutes were not significantly different and, therefore, the mean of the values at these three times was calculated and considered as a plateau. The choker was then abruptly occluded and

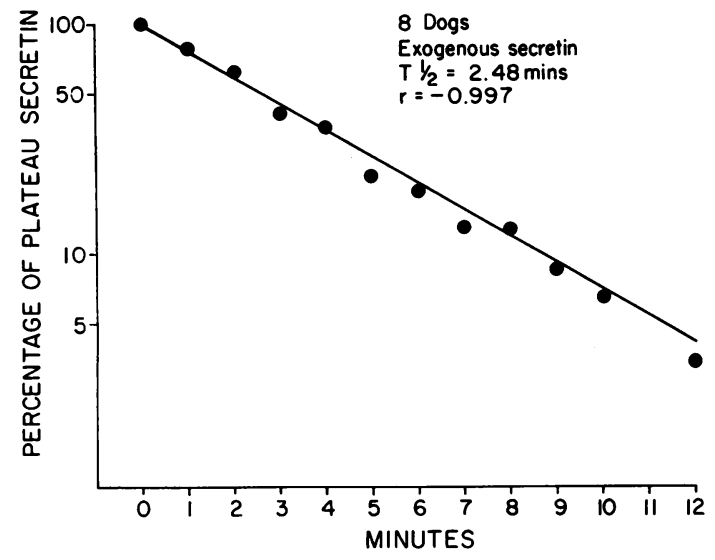

Fig. 2 Regression line of plasma secretin after a constant infusion of pure natural secretin, $1.5 \mathrm{U} / \mathrm{kg}$ body weight.

secretin levels fell rapidly to $190 \pm 33 \mathrm{pg} / \mathrm{ml}$ at 26 minutes and reached basal values by 32 minutes (Fig. 3). When the postperfusion secretin concentrations were plotted in a semilogarithmic fashion against time, a linear relationship was again found; the line had a slope of -0.243 and a correlation coefficient of -0.985 (Fig. 4). The disappearance halftime was 2.85 minutes.

\section{Discussion}

The data from these experiments show that both exogenous natural porcine secretin and endogenous canine secretin are rapidly removed from the circulation of dogs. The two half-lives calculated, 2.45 minutes for infused porcine secretin and 2.85

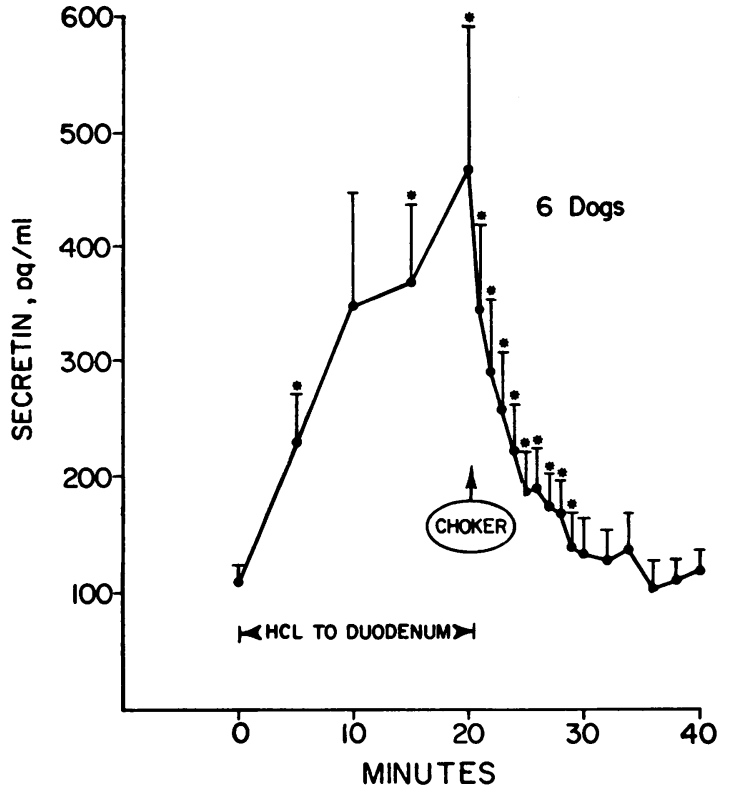

Fig. 3 Concentration of secretin in plasma before, during, and after irrigation of duodenum and proximal jejunum with $0.1 \mathrm{~N}$ hydrochloric acid, $1.5 \mathrm{mEq} / \mathrm{min}$, for 20 minutes, followed by occlusion of veins draining the stimulated area. Asterisks denote significant elevations above basal $(\mathrm{P}<0.05)$.

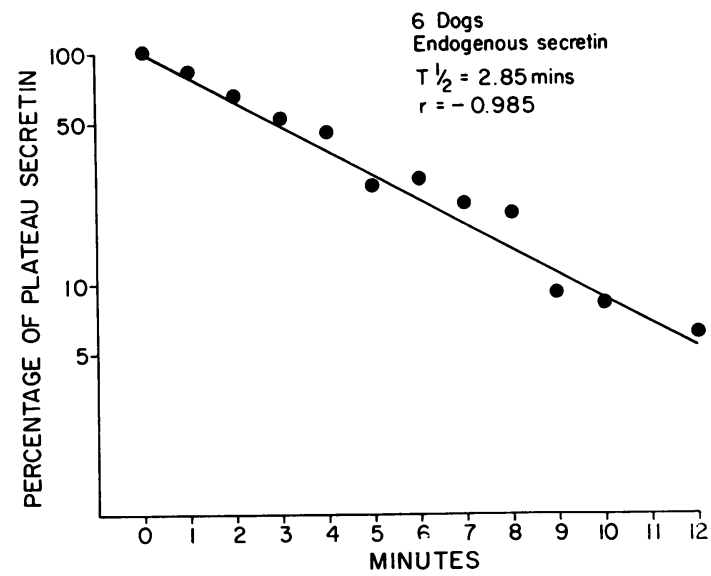

Fig. 4 Regression line of plasma secretin after occlusion of veins draining secretin-releasing segment of bowel.

minutes for endogenous secretin, are in general agreement with the half-time of 2.8 minutes for infused secretin in three dogs calculated by Boden $e t$ al. (1974) from radioimmunoassay data. 
Bioassay methods of quantitating secretin, employing pancreatic secretory response, have shown the disappearance half-time in the dog to be $3 \cdot 2$ minutes (Lehnert et al., 1969), in the cat $3 \cdot 3$ minutes (Clark et al., 1967), and in the pig three to four minutes (Hubel, 1972). In each of these investigations, either pure porcine or synthetic secretin was infused to determine the half-life of the hormone. Lagerlöf et al. (1962) calculated the half-life of secretin in man to be 17 minutes, as judged by pancreatic response.

The plasma secretin levels generated by infusion of secretin or by duodenal perfusion with $\mathrm{HCl}$ are greatly in excess of levels so far measured in physiological circumstances, and this should be taken into account when assessing the half-life times. Previous work has shown the metabolic clearance rates to vary with the dose of hormone administered and the serum levels achieved (Clendinnen et al., 1973), but, in the present investigation, secretin levels after infusion of exogenous hormone were higher than after release of endogenous secretin $(632 \pm 41 \mathrm{pg} / \mathrm{ml}$ against $389 \pm 56 \mathrm{pg} / \mathrm{ml}$ ) and the $\mathrm{T}_{\frac{1}{2}}$ was slightly shorter (2.45 minutes against 2.85 minutes).

By allowing the plasma concentration to reach a near-plateau state before starting disappearance half-time studies, we hoped to avoid errors due to mixing phenomena occurring after termination of the infusion or isolation of the secreting segment of bowel.

Disappearance half-time measurements of each of the different molecular forms of gastrin available in a pure state are related to their molecular size: tri-

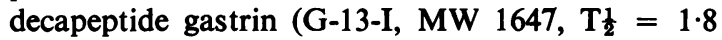
minutes (Debas et al., 1974)); heptadecapeptide

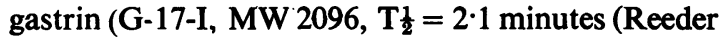
et al., 1972)); big gastrin (G-34-I, MW 3839, T1 $\frac{1}{2}=9$ minutes (Straus and Yalow, 1974), $\mathrm{T} \frac{1}{2}=15$ minutes (Walsh et al., 1974)). The disappearance half-time of endogenous antral gastrin in dogs measured by Thompson et al. (1975) was 8.6 minutes, which presumably represents the half-time of the mixture of molecular forms of gastrin circulating in peripheral blood.

Straus et al. (1975) subjected extracts of duodenal mucosa to gel fractionation on columns of Sephadex G50, and found two peaks of secretin immunoreactivity, one appearing in the same position in the elution pattern as synthetic human secretin (27 amino acids), and a second peak appearing near the void volume, suggesting the presence of a larger molecular form of the hormone. These findings have been extended by Boden et al. (1975) who fractionated duodenal extracts by a similar method and found a 'small' secretin, probably the 27-amino acid form, a 'big' secretin, eluting between human growth hormone and insulin, and also secretin immunoreactivity eluting in the void volume.

Pure natural porcine secretin (GIH) has been shown to consist of one molecular form with 27 amino acids (Jorpes, 1968). The close correlation between the half-lives of this hormone and endogenous canine secretin suggests that the hormone released from the duodenum by mucosal acidification and measured in the radioimmunoassay of only one molecular form, or that the half-lives of variant forms of secretin are similar to that of 27amino acid secretin (S-27), or that, for some reason, our antibody does not recognize other forms of secretin.

\section{References}

Bayliss, W. M., and Starling, E. H. (1902). The mechanism of pancreatic secretion. Journal of Physiology, 28, 325-353.

Boden, G., Essa, N., Owen, O. E., and Reichle, F. A. (1974). Effects of intraduodenal administration of $\mathrm{HCl}$ and glucose on circulating immunoreactive secretin and insulin concentrations. Journal of Clinical Investigation, 53, 11851193.

Boden, G., Murthy, N. S., and Silver, E. (1975). "Big" secretin. Clinical Research, 23, 245A.

Clark, D. G., Greenwell, J. R., Harper, A. A., Sankey, A. M. and Scratcherd, T. (1967). The electrical properties of resting and secreting pancreas. Jourral of Physiology, 189, 247 260.

Clendinnen, B. G., Reeder, D. D., Brandt, E. N., Jr, and Thompson, J. C. (1973). Effect of nephrectomy on the rate and pattern of the disappearance of exogenous gastrin in dogs. Gut, 14, 462-467.

Debas, H. T., Walsh, J. H., and Grossman, M. I. (1974). Pure human minigastrin: secretory potency and disappearance rate. Gut, 15, 686-689

Goldstein, A., Aronow, L., and Kalman, S. M. (1968). Zero-order absorption, first-order elimination: the plateau principle. In Principles of Drug Action, pp. 292 317. Harper and Row: New York.

Greenwood, F. C., Hunter, W. M., and Glover, J. S. (1963). The preparation of ${ }^{131}$ I-labelled human growth hormone of high specific radioactivity. Biochemical Journal, 89, 114 123.

Heatley, N. H. (1968). The assay of secretin in the rat. Journal of Endocrinology, 42, 535-547.

Hubel, K. A. (1972). Secretin: a long progress note. Gastroenterology, 62, 318-341.

Ivy, A. C., and Janecek, H. M. (1959). Assay of Jorpes-Mutt secretin and cholecystokinin. Acta Physiologica Scandinavica, 45, 220-230.

Jorpes, J. E. (1968). The isolation and chemistry of secretin and cholecystokinin. Gastroenterology, 55, 157-164.

Jorpes, J. E., and Mutt, V. (1959). Secretin, pancreozymin, and cholecystokinin. Their preparation and properties. Gastroenterology, 36, 377-385.

Lagerlöf, H., Ek, S. Y., and Nyberg, A. (1962). The duodenal secretion in man as a function of secretin dose and secretin inactivation. Gastroenterology, 43, 174-180.

Lehnert, P., Stahlheber, H., Forell, M. M., Dost, F. H., Fritz, H., Hutzel, M , and Werle, E. (1969). Bestimmung der Halbwerlszeit von Secretin. Klinische Wochenschrift, 47, 1200-1204.

Mutt, V., and Söderberg, A. (1959). On the assay of secretin. Arkiv fur Kemi, 15, 63-68. 
Odell, W. D., Rayford, P. L., and Ross, G. T. (1967). Simplified, partially automated method for radioimmunoassay of human thyroid-stimulating, growth, leuteinizing, and follicle stimulating hormones. Journal of Laboratory and Clinical Medicine, 70, 973-980.

Rayford, P. L., Curtis, P. J., Fender, H. R., and Thompson, J. C. (1976) Plasma levels of secretin in man and dogs: validation of a secretin radioimmunoassay. Surgery. 79, 658-666.

Reeder, D. D., Jackson, B. M., Brandt, E. N., Jr, and Thompson, J. C. (1972). Rate and pattern of disappearance of exogenous gastrin in dogs. American Journal of Physiology, 222, 1571-1574.

Robard, D. (1971). Statistical aspects of radioimmunoassays. In Principles of Competitive Protein-Binding Assays, pp. 204-253. Edited by W. D. Odell and W. H. Daughaday. Lippincott: Philadelphia.
Straus, E., and Yalow, R. S. (1974). Studies on the distribution and degradation of heptadecapeptide, big and big big gastrin. Gastroenterology, 66, 936-943.

Straus, E., Urbach, H., and Yalow, R. S. (1975). Secretin RIA: methodology and application to studies of distribution and molecular forms of secretin in tissues. Presented to the Endocrine Society, June 1975, New York.

Thompson, J. C., Rayford, P. L., Ramus, N I., Fender, H. R., and Villar, H. V. (1975). Patterns of release and uptake of heterogeneous forms of gastrin. In Gastrointestinal Hormones, pp. 125-151. Edited by J. C. Thompson. University of Texas Press: Austin.

Walsh, J. H., Debas, H. T., and Grossman, M. I. (1974). Pure human big gastrin; immunochemical properties, disappearance half time and acid-stimulating action in dogs. Journal of Clinical Investigation, 54, 477-485. 